\title{
Improving students' articulatory fluency in English through Speech Smart Module
}

\author{
Adrian V. Protacio
}

English Department, College of Teacher Education, Sultan Kudarat State University, Mindanao, Philippines

Received: 09 Feb 2021; Received in revised form: 19 Apr 2021; Accepted: 10 May 2021; Available online: 23 May 2021

C2021 The Author(s). Published by Infogain Publication. This is an open access article under the CC BY license

(https://creativecommons.org/licenses/by/4.0/).

\begin{abstract}
The strategy of learning modules provides meaningful learning experiences to students, and has become a part of all-level teaching. This study sought to evaluate the Speech Smart Module (SSM) and to identify its effect on students' articulatory fluency in the subject of speech and oral communication. This was conceptualized to address students' problems in articulating segmental and suprasegmental sounds of English, lack of self-confidence, and lack of relevant and effective instructional materials. The study employed an experimental research design. The SSM as evaluated by content experts was rated very highly valid as to contents, relevance, acceptability, and instructional quality. Respondents of the study comprised students of Bachelor of Secondary Education (BSED) at Sultan Kudarat State University. Students were divided into control group $(C G)$ and experimental groups $(E G)$ based on their scores and level in the Job Enabling English Proficiency (JEEP) Placement Test. The SSM was employed as treatment in the EG group while traditional teaching was used in CG. After four (4) months of study, results revealed the effectiveness of SSM as instructional material in improving EGs' articulatory fluency level from poor to excellent whereas the CG had relatively improved from poor to fair. Hence, it is recommended to utilize the SSM among college students and for those who wish to improve their articulatory fluency and communication skills in English in general.
\end{abstract}

Keywords-Module, Pronunciation, Experimentation, Articulation, Second Language Acquisition.

\section{INTRODUCTION}

English is a language that is used to communicate across borders(Varasarin, 2007). Many citizens are eager to learn and speak English with proper pronunciation(Hassan, 2014). Hence, English teachers should focuson the growth of students' competence and concentrate on a more effective and meaningful approach to meet the demands of modern society.

People now live in a time when being able to communicate fluently in a second language (L2) has become a requirement, especially for those wishing to advance in certain fields of human endeavor. As a result, oral fluency is a key feature of L2 expression, which is often assessed when assessing second language abilities(Derwing et al., 2004).
However, segmental errors frequently occur in English as a second language (ESL) due to differences between first language (L1) and L2 and the way a language is taught has some effect on the learning of English (Ali, 2013). Although good pronunciation is expected when students step in the tertiary level, segmental and suprasegmental mispronunciationis evident among students of Sultan Kudarat State University (SKSU). This situation was found during the Oral Diagnostic Test (ODT) since it revealed that most of the second-year college students were descriptively rated as poor and needs improvement. Additionally, there was a lack of palpable instructional material which eventually demotivates students to learn the English language.

Similarly, the problem was confirmed during informal interviews with English professors and instructors. Students had been struggling in speaking English as the 
medium of instruction and communication since they have difficulties and confusion as to the appropriate production of the speech sounds. These were manifested during classroom oral reports, recitations, and other oral activities. Lack of self-confidence in speaking, poor basic skills of the speech sounds, and production of the distinctive regionalized accents are inevitable problems for many SKSU students who learn ESL. Basically, many studies have demonstrated that theseproblems and challenges are made by the speakers of other languages who speak English (Hassan, 2014).

These prevailing problems had enlightened the researcher to initiate and innovate a strategy in teaching which aims to gradually eliminate these dismal issues on articulation and support students to effectively communicate in English.

Besides, finding ways to help students improve their oral fluency is an important challenge in teaching English as a second language (ESL) This is especially true in countries where learners share a common mother tongue and have little or no exposure to the L2 outside the classroom (AlSibai, 2004).

Hence, Wood (2001) suggests that empirical research focusing on fluency has generally involved the elicitation of a speech corpus as well as the analysis of temporal and qualitative aspects of speech productions. This research examined the articulatory fluency problems of college students and these problems became the basis of developing a palpable speech module.

The researcher developed Speech Smart Moduleas instructional material (IM) centered on segmental and suprasegmental features of English. Experimentation was the prime move of the study and the intention was to test its effectiveness as an approach in improvingstudents' articulatory fluency.

\section{Objectives and Research Questions}

The study focused on the evaluation and effectiveness of the Speech Smart Module (SSM) as an intervention in improving students'articulatory fluency in the English language. The objectives include:

1. to validate the researcher-developed module particularly on contents, relevance, acceptability, and instructional quality in reference to the evaluation of content experts; and,

2. to determine the effect of SSM in improving the articulatory fluency of students in the English language.

Specifically, it answered the following research questions:
1. What is the level of validity of the SSM in terms of contents, relevance, acceptability, and instructional quality based on the assessment of content experts?

2. What is the effect of the SSM in improving the articulatory fluency of students in English?

\section{METHODS}

The participating institution was the Sultan Kudarat State University specifically in the College of Teacher Education located at ACCESS Campus, EJC Montilla, Tacurong City, Sultan Kudarat, Philippines.

\section{Research Design}

An experimental Research Design was employed in the study. It also describes and compares the distinct characteristics of the performance of students in the control and experimental groups (Beaumont, 2009).

\section{Respondents of the Study}

The respondents were the second-year students enrolled in the subject Speech and Oral Communication (SOC) from the Bachelor of Secondary Education in the First Semester of Academic Year 2017 to 2018. The studentrespondents were classified into control and experimental groups based on their diagnostic results Job Enabling English Proficiency (JEEP) Start Program-Placement Test to determine their level of English proficiency. The researcher only included the respondents by their comparable scores in the placement test that ranges from 0.2 to 0.7 which means "beginner" in English language learning.

The SSM was employed as instructional material in teaching SOC in the experimental groups. Meanwhile, traditional teaching was used in the control group. The researcher himself taught the subject among the groups which lasted for four (4) months.

\section{Research Instrument}

The prime instrument of the study was the Speech Smart Module (SSM). A self-contained and individualized self-instructional package, which could assist students to achieve a wide range of objectives at their own pace. Topics comprised speech, oral communication, listening and speaking processes, segmental (vowel and consonant sounds, diphthongs with drills, pattern drills, minimal pairs) to suprasegmental features of English (stress, intonation contours) tunes in speaking, modes of speaking presentation up to oral and group ensembles.

The SSM was validated and evaluated by five (5) content experts in English language teaching, research, and instructional material development. The identification of 
the validators was based on the following inclusion criteria: (a) must be a holder of an appropriate doctorate degree; (b) must-have experiences in teaching English as a second language for at least ten (10) years; (c) must-have experiences in research and instructional material development; and (d) must be a college or university professor.

Additionally, the SSM was validated in reference to the criteria used in the evaluation of modules as suggested by Herrera (2011). It was a five-point Likert scale instrument with numerical rating, mean range, verbal description, and interpretation. Likewise, similar pretest and posttest instrument was also used to identify the level of oral performance of respondents in the control and experimental groups.

\section{Data Gathering Procedure}

After the approval was obtained from the offices of VicePresident for Academic Affairs and Dean, the researcher conducted an oral pretest utilizing a camera-recorder among all groups. Then, the SSM was integrated into the experimental group while traditional teaching was carried out in the control group.

After the experimentation, the posttest was conducted. Then, data gathered were tallied, tabulated, and analyzed. The researcher sought the assistance of a statistician purposely to assess the veracity of the analysis.

\section{Statistical Treatment}

Mean was used in the evaluation and validation of the SSM in terms of its content, relevance, acceptability, and instructional quality. Hence, it was also used to describe the respondents'oral performance in pretest and posttest of control (CG) and experimental groups (EG).A t-test was utilized for the computation of the significant difference in the articulatory fluency level between control and experimental groups in the pretest and post-test, and a significant difference between the mean gain scores on articulatory fluency level. In all statistical tests, the level of significance was set at $\alpha=.05$.

\section{RESULTS}

Table 1 reveals the validity of the Speech Smart Module (SSM). The SSM was evaluated by the content experts as very highly valid as to its contents, relevance, acceptability, and instructional quality. This means that the module provides substantial concepts and offers students opportunities to improve their articulation in different communicative settings.

Hence, Ambayon (2020) conducted validation and experimentation to test the effectiveness of the modular approach in teaching literature. He then, points out that a module must be acceptable, relevant, valid, reliable, and useable. Hence, IMs for students' use must be anchored on how the course must be taught. For Tugade (2020), modules are built in two stages: the design stage explored learning competencies and the identification and selection of reference materials; and the implementation stage included the writing of goals, principles, abilities, and learning tasks, as well as the pretest and posttest. Subsequently, any teacher's decision in preparing, selecting, and utilizing modules must be aligned with what the students need to develop in terms of knowledge (Gurra, 2001).

In this study, the SSM was rated very highly valid since it is congruent to the curriculum goals, learning objectives, sequence of activities, directions, exercises, logical order, experiential learning, and flexibility. It considers students experiences and needs, desired language skills, and communicative competence, meets the minimum requirements for a course, suitability for individual use. It ruminates students to gain confidence in speaking, to insights in real-life situations, to develop language facility. Further, the SSM has good usage like handling and manipulations, suitabilityto the target students and their learning needs, understandable directions and nonthreatening to multicultural students, variety of exercises for active and spontaneous learning, stimulate students curiosity and interest, and strong relevance to students' experiences.

In Table 2, students from the control and experimental groups performed poorly in articulating segmental and suprasegmental sounds in English and they were below $21 \%$ articulatory fluency during the pretest. More or less homogeneous, the students are not familiar with or may have been struggling in producing appropriate sounds in English.Likewise, Derwing et al. (2004) discover that only $10 \%$ of students' recorded pronunciation issues were linked to prosody when they studied adult English as a second language (ESL) pronunciation difficulties and strategies. Similarly,Zhang and Yin (2009), some English learners prefer "dumb English" and as consequence, they are shocked whenever they meet difficulties in oral communication.

Additionally, in Table 3, a t-test was run and the result unveils that there is no significant difference in the pretest scores of students control and experimental groups. The computed t-value of 1.98 is less than a critical value of 2.02 at a 0.05 level of significance. Hence, there is sufficient evidence that the experimental performs with similar prior knowledge of articulation compared to the control group. 
After the experimentation,it can be inferred that both groups have seemingly improved their articulatory fluency level. However, the experimental group obtained a higher performance.The control group who were taught the traditional way had improved to a fair level. Thus, a minimal improvement of articulatory fluency was evident meeting its 21 to $40 \%$ standard. On the other hand, the experimental group had advanced to an excellent level and meeting the $81 \%$ of articulatory fluency level (Table 2).

In Table 4 , the $t$-test analysis on posttest scores of the control and experimental groups in articulatory fluency is presented. The computed t-value of 15.62 is greater than the critical value of 2.02 at a $5 \%$ level of significance. The result indicates that a difference of 2.13 between the means of the two (2) groups is indeed substantial to be considered. Thus, it can be inferred that the experimental group where the SSM was employed caused sufficient, effective, and efficient learning to students compared to the control group who were taught the traditional teaching.

Similarly, the result is supported by Ali et al. (2005). They proved theeffectiveness of learning modules to students as compared to traditional teaching methods. It is stressed that in modular teaching, students are given opportunities of learning at their own pace, according to their abilities and needs. At the same time, it is very effective to the lowachievers since immediate reinforcement is provided.

In Table 5, the computed t-value of 10.20 is greater than the critical value of 2.02 at a $5 \%$ level of significance Hence, there is sufficient evidence to claim that the experimental group has a higher mean gain score compared to the control group. It means that when the SSM contributed immensely to the improvement of students' articulatory fluency level.

Table 1. Level of validity of the SSM as evaluated by content experts in terms of content, relevance, acceptability, and instructional quality.

\begin{tabular}{llll}
\hline Level of Validity & M & Verbal Description & Interpretation \\
\hline Content & 4.62 & Very Highly Valid & meets 81\% ofvalidity \\
Relevance & 4.51 & Very Highly Valid & meets $81 \%$ of relevance \\
Acceptability & 4.48 & Very Highly Valid & meets $81 \%$ of acceptability \\
Instructional Quality & 4.50 & Very Highly Valid & meets 81\% of quality \\
\hline
\end{tabular}

Key: Very Highly Valid $(M=4.30-5.00)$; Highly Valid $(M=3.40-4.29)$; Moderately Valid $(M=2.60-3.39)$; Less Valid $(M=1.80-2.59)$, Least Valid $(M=1.00-1.79)$

Table 2. Level of articulatory fluency of students in control and experimental groups in pretest and posttest

\begin{tabular}{|c|c|c|c|c|c|c|}
\hline Groups & Pretest & $\begin{array}{l}\text { Verbal } \\
\text { Description }\end{array}$ & Interpretation & Posttest & $\begin{array}{l}\text { Verbal } \\
\text { Descriptio } \\
\text { n }\end{array}$ & Interpretation \\
\hline Control & 1.27 & Poor & $\begin{array}{l}\text { below } 21 \% \text { of } \\
\text { articulatory fluency }\end{array}$ & 2.29 & Fair & $\begin{array}{l}\text { meets } 21-40 \% \text { of } \\
\text { articulatory fluency }\end{array}$ \\
\hline Experimental & 1.67 & Poor & $\begin{array}{l}\text { below } 21 \% \text { of } \\
\text { articulatory fluency }\end{array}$ & 4.42 & Excellent & $\begin{array}{l}\text { meets } 81 \% \text { of articulatory } \\
\text { fluency }\end{array}$ \\
\hline
\end{tabular}

Key: Excellent $(M=4.30-5.00)$; Very satisfactory $(M=3.40-4.29)$; Satisfactory $(M=2.60-3.39)$; Fair $(M=1.80-2.59)$, Poor $(M=1.00-1.79)$

Table 3. $t$-test analysis on pretest scores of the control and experimental groups in articulatory fluency

\begin{tabular}{llllllll}
\hline Groups & N & M & SD & Mean Difference & df & Computed t & Tabular Value \\
\hline Control & 20 & 1.27 & 0.30 & 0.4 & 38 & $1.98 \mathrm{~ns}$ & 2.02 \\
Experimental & 20 & 1.67 & 0.65 & & & & \\
\hline
\end{tabular}

Key: $\propto=0.05$ level of significance, ns - not significant 
Table 4. $t$-test analysis on posttest scores of the control and experimental groups in articulatory fluency

\begin{tabular}{llllllll}
\hline Groups & N & M & SD & Mean Difference & df & Computed t & Tabular Value \\
\hline Control & 20 & 2.29 & 0.44 & 2.13 & 38 & $15.62^{*}$ & 2.02 \\
Experimental & 20 & 4.42 & 0.42 & & & & \\
\hline
\end{tabular}

Key: $\propto=0.05$ level of significance, $*$ - significant

Table 5. t-test result of the mean gain scores of the control and experimental groups in articulatory fluency

\begin{tabular}{llllllll}
\hline Groups & N & M & SD & Mean Difference & df & Computed t & Tabular Value \\
\hline Control & 20 & 1.02 & 0.50 & 1.73 & 38 & $10.20^{*}$ & 2.02 \\
Experimental & 20 & 2.75 & 0.57 & & & & \\
\hline
\end{tabular}

Key: $\propto=0.05$ level of significance, $*$ - significant

\section{DISCUSSION}

The strategy of learning modules has become a part of all levels of teaching. A learning module is a self-learning package dealing with one specific subject matter unit. It can be used in any setting convenient to the learner and may be completed at the learner's own pace. It may be used individually or in small groups (Ali et. al., 2010).

A module is a unit of work in a course of instruction that is virtually self-contained and a method of teaching that is based on building up skills and knowledge in discrete units (Sejpal, 2013).Loughran and Berry (2000) point out that in module learning, teachers becomes a facilitator rather than the traditional dispenser of knowledge. Sufficient theory and practice are available for the application of modular teaching in the classrooms.

The study of Huckabay (2000) emphasizes that the use of modules in teaching is overwhelmingly preferred by many nursing students. As a result, students who were enrolled in the class did acquire significantly more cognitive knowledge as evaluated from objective to subjective tests. In support, Venkatagiri and Levis (2007) stress that the maintenance of explicit modular instruction can help students develop phonological awareness (i.e. conscious knowledge of segmental and suprasegmental), which might play a key role in second language speech intelligibility.

However, IMs are designed not to replace the teacher or to reduce the work but to improve quality education. Overall, modular teaching is important in pedagogical practices because it better addresses cognitive, affective, and psychomotor skills than traditional teaching methods encourages more engaging sessions, and promotes learning through active thinking(Srikanth, Behera \& Mahajan, 2011).
The teaching and learning modules of a unit are designed to include the knowledge, methods, and skills students should receive from the delivery of the unit. For Donnelly and Fitzmaurice (2005), in the process of devising a module, the key is to forge educationally sound and logical links between learner needs, aims, learning outcomes, resources, learning and teaching strategies, assessment criteria, and evaluation. According to Ali (2010 \& 2005), the components of a learning module include instructions on how to use the modules, purpose, and aims, list of prerequisite skills, list of instructional objectives, diagnostic pretest, sequenced instructional activities, mastery posttest, and feedback and/or reinforcement.

Similarly, among the various systems of individualized instruction proposed so far, modular instruction is one of the newest and combines many advantages of several separate instructional innovations, such as performance objectives, self-pacing, and frequent feedback (Buasag, 2013). Moreover, the study of Larawan (2013) determined the acceptability of teacher-designed programmed modules in production management for classroom learning using the evaluations of expert jurors and student-users. Using separate and combined assessments of the two groups of evaluators, the findings showed that the modules are generally very satisfactory in terms of physical aspects, goals, instructions, learning, and evaluative instrument. This demonstrates that they are suitable as a learning intervention, and the assessment paves the way for the creation of a self-learning framework tailored to the specificities of unique individuals.

\section{CONCLUSIONS}

Based on the results and thorough analyses, the succeeding conclusions are drawn. The Speech Smart Module as interventional-instructional material has very 
highly valid contents, relevance, acceptability, and instructional quality. SSM was an effective and efficient treatment and strategy that had excellently advanced students' articulatory fluency level thereby, supporting students' independent learning, enhancing self-confidence in different communicative settings, and in honing communicative competence and public speaking skills in English.

\section{REFERENCES}

[1] Ali, R. (2005). Development and effectiveness of modular teaching in biology at the secondary level. [Unpublished Doctoral Dissertation] University of Arid Agriculture, Rawalpindi, Pakistan

[2] Ali, R., Ghazi, S. R., Khan, M. S., Hussain, S., \& Faitma, Z. T. (2010). Effectiveness of modular teaching in biology at secondary level. Asian Social Science, 6(9), 49. https://pdfs.semanticscholar.org/a002/4b15d7c55edbebe3a 42cc1dfe58b98209760.pdf

[3] Al-Sibai, D. (2004). Promoting oral fluency of second language learners: Adult learners of English. Educational Linguistics Department of English. King Saud University. http://eprints.ums.ac.id/34624/12/08.\%20BIBLIOGRAPH Y.pdf

[4] Ambayon, C. (2020). Modular-based approach and students' achievement in literature(EJ1264560). ERIC. https://files.eric.ed.gov/fulltext/EJ1264560.pdf

[5] Beaumont, R. (2009). Research methods and experimental designs: A sets of notes suitable for seminar use. http://www.floppybunny.org/robin/web/virtualclassroom/c hap16/s1/sembk2.pdf

[6] Buasag, J. V. (2013, March 16). Modular teaching. https://www.slideshare.net/joshvennbuasag/modularinstruction

[7] Derwing, T., Rossiter, M., Munro, M. \& Thomson, R. (2004). Second language fluency: judgments on different tasks. Language Learning, 54 (4), 655-679. http://faculty.ksu.edu.sa/yousif/Supporting\%20Articles/sec ond $\% 201$ anguage $\% 20$ fluency $\% 202004$.pdf

[8] Donnelly, R., \& Fitzmaurice, M. (2005). Collaborative project-based learning and problem-based learning in higher education: A consideration of tutor and student roles in learner-focused strategies. Emerging issues in the practice of university learning and teaching, 87-98. http://eprints.teachingandlearning.ie/2917/1/McCarthy\%20 and\%20Higgs $\% 202005$.pdf\#page $=97$

[9] Gurra, M. A. (2009). Module in teaching fundamentals of rhythmic activities: Development and validation. [Unpublished Master's Thesis]. Sultan Kudarat State University, Philippines.

[10] Hassan, E. M. I. (2014). Pronunciation problems: A case study of English language students at Sudan University of Science and Technology. English Language and Literature Studies, 4(4), http://www.ccsenet.org/journal/index.php/ells/article/downl oad $/ 42575 / 23274$
[11] Herrera, R. G. (2011). Computer-Assisted Instruction (CAI) in English and student's performance. [Unpublished Master's Thesis]. Sultan Kudarat State University, Philippines

[12] Huckabay, L. M. (2009, July). Partnership between an educational institution and a healthcare agency-Lessons learned: part I. In Nursing forum (Vol. 44, No. 3, pp. 154164). Blackwell Publishing Inc.

[13] Larawan, L. (2013). Acceptability of teacher-made modules in production management. International Journal of Managerial Studies and Research (IJMSR), 1(2), 10-22. https://citeseerx.ist.psu.edu/viewdoc/download?doi=10.1.1. $678.5524 \&$ rep $=$ rep $1 \&$ type $=$ pdf

[14] Loughran, J. \& Berry, A. (2000). Improving teacher education practice through self-study. Routledge Lamer, 28 West, $35^{\text {th }}$ Street, New York, USA. pp 28

[15] Metler, CA (2017). Quantitative research methods. https://us.sagepub.com

[16] Sejpal, K. (2013). Modular method of teaching. International Journal for Research in Education Vol. 2,(2), Feb. 2013 (IJRE) ISSN: 2320-091X. https://raijmronlineresearch.files.wordpress.com/2017/07/2 9_169-171-dr-kandarp-sejpal.pdf

[17] Srikanth, S., Behera, B., \& Mahajan, P. (2011). Modular teaching: an alternative to routine teaching method for undergraduate medical students. Indian journal of community medicine: official publication of Indian Association of Preventive \& Social Medicine, 36(3), 237238.

https://www.ncbi.nlm.nih.gov/pmc/articles/PMC3214453/

[18] Tugade, G. (2020). Development and validation of learning module in TLE dressmaking. UNP Research Journal, 25(1), 59-75. http://journal.unp.edu.ph/index.php/unprj/article/view/136

[19] Varasarin, P. (2007). An action research study of pronunciation training, language learning strategies and speaking confidence [Doctoral dissertation, Victoria University]. http://eprints.vu.edu.au/1437/1/Varasarin.pdf

[20] Venkatagiri, H. S., \& Levis, J. M. (2007). Phonological awareness and speech comprehensibility: An exploratory study. Language awareness, 16(4), 263-277. https://www.researchgate.net/profile/John_Levis/publicatio $\mathrm{n} / 233367704$

[21] Wood, D. (2001, June). In search of fluency: What is it and how can we teach it?. Canadian Modern Language Review, $57 \quad$ (4), $573-589$ https://utpjournals.press/doi/abs/10.3138/cmlr.57.4.573

[22]Zhang, F., \& Yin, P. (2009). A study of pronunciation problems of English learners in China. Asian social science, 5(6), https://pdfs.semanticscholar.org/4732/7dad6066a0a6aa1e3 7a83b5ac8a5d236a583.pdf 